\title{
Reviving reasonableness: Expansive reason-giving and receiving for global social justice education
}

\author{
Derek Tannis \\ University of Alberta \& University of Saskatchewan \\ derek.tannis@ualberta.ca
}

\begin{abstract}
Reasonableness is a term that is used widely in relation to global social justice, yet its meaning differs depending on its theoretical foundations. In this paper, I examine the breadth of these meanings, focusing on the pedagogical significance of reasonableness as something that is assessed, recognized and enacted. I present a model of reasonableness that expands upon Erman's (2007) concept of reason-giving and is founded upon the philosophy of inter-subjective recognition as described by Honneth (1996) and the idea of capabilities as theorized by Sen (2009) and Nussbaum (2005). I develop a typology of reason-giving and reason-receiving, including arbitrary, emotive, authoritative, tentative and expansive analytical-relational modes. I conclude that the assertion of another person's reasonableness / unreasonableness may be viewed as an inter-subjective and intercultural lived relation. Approximating the cosmopolitanism proposed by Nussbaum (2005) and Appiah (2006), I propose that we should aim to create learning approaches and environments that foster exploratory and compassionate reason-giving and receiving. In an era of global social justice discourse and action, I argue that cultivating a reflective approach to reason-giving and receiving would develop in students an expansive conception of and capacity for reasonableness.
\end{abstract}

\section{Introduction: Reasonableness on trial}

Global social justice can be described as many things, from being a process of deliberation to constituting a comprehensive moral philosophy. It is celebrated as a work in progress and contested as an ideological dead end. Incommensurable worldviews, conflicting ways of life and global inequities cast shadows into the most positive instances of global social justice. Meta-political and substantive models of global cooperation and intervention crumble into vernacular fallout due to seemingly incomprehensible acts of violence, greed, selfrighteousness and corruption. At such times, we often take our positions and let our words and actions belie our biases. At opposite ends of the spectrum, interlocutors, from global leaders to local activists to kitchen table politicians, question one another about their commitment to global social justice, shake their heads or fists, proclaiming equally the unreasonableness of the other.

Throughout history claims of unreasonableness have reached levels of frenzy and fundamentalism, resulting in inhumane behaviour. The sentencing of 20 innocent people to death in the bizarre Salem witch trials of Massachusetts in 1692 is one such example (Martine, 1993). Miller (1953/1979) dramatized these events in his play, The Crucible and his intention was clear: at that time, the McCarthy hearings of the House Un-American Activities Committee in Washington were underway, instilling fear and suspicion across his country (Martine, 1993). Miller was questioned by the committee as a suspected communist sympathizer, facing an

Cultural and Pedagogical Inquiry, 2012, 4(2), pp. 4-20

ISSN 1916-3460 (C 2012 University of Alberta

http://ejournals.library.ualberta.ca/index.php/cpi/index 
interrogator who likely spoke similar words as those of Judge Danforth in The Crucible, "A person is with this court or he must be counted against it, there be no road between." (1953/1979, p. 94). 50 years later, George W. Bush would issue a similar warning on a global scale. He would disregard the UN Assembly, determined to invade and occupy a country for reasons that were disproved soon after victory declared.

Disparate global conflicts are the fodder of the Hobbsian-inspired belief that humanity is naturally inclined to violence and self-interest and, therefore, we elect to create and submit to sovereign states for our protection and self-preservation (Beitz, 2008). Subsequent realist perspectives on global social justice ground such perceived unavoidable conflict in ideological accounts of race, gender, culture, religion and nationality (Dryzek, 2006). Concurrently, however, such conflicts are also the foundation of a deliberative global politics that is open to disagreement and difference, encouraging analysis of issues and seeking mutuality in our seemingly unreasonable human condition (Mendieta, 2009; Sen, 2009). In this paper, I examine the lived meanings of global social justice from this deliberative, dialogical and reflective practice, as described by Dryzek (2006) and Fraser (2009). From an educational standpoint, the question I address is: "How can we create learning environments that foster characteristics of reasonableness in relationship to matters of global social justice?”

To explore reasonableness pedagogically, it must be examined in relation to how it is known, assessed and enacted. In the first section of this paper, I discuss my rationale for reconceiving reasonableness, both conceptually and pedagogically, in relation to global citizenship education. In the next sections, I consider reasonableness as a form of judgement and recognition. This first view of reasonableness involves a spectrum of criteria, including flexibility/inflexibility in the face of difference, means/ends as a source of justification, subjectivity/objectivity as the principle perspective of interpretation, and universality/particularity in relation to moral reasoning. This second view of reasonableness addresses issues of understanding, affirmation, experience and mutuality. In the fourth section, I introduce a model of reasonableness that combines relational and analytical modes of reasonreceiving/giving. The model expands upon Erman's (2007) concept of reason-giving and is founded upon the philosophy of inter-subjective recognition as described by Honneth (1996) and the concept of capabilities as theorized by Sen (2009) and Nussbaum (2005). I present a typology of reason-receiving and giving, including arbitrary, emotive, authoritative, tentative and expansive analytical-relational modes. In the final section of the paper, I reflect on the educational significance of the proposed model. Approximating the cosmopolitanism proposed by Nussbaum (2005a; 2005b) and Appiah (2006), I contend that we should aim to create learning approaches and environments that foster exploratory and compassionate reason-giving and receiving through self-, inter-subjective and intercultural awareness.

An acknowledged limitation of this paper is that I rely upon a survey and synthesis of European and North American political philosophy and ethics. I do not provide a deeply historical-philosophical or multicultural analysis, nor do I include non-Western philosophical traditions. I have, however, integrated a post-modern critical lens and feel that the model and ideas presented are open to critique, deconstruction and elaboration. My purpose was not to create a universal concept, but to document how I have made sense of what I see as a pervasive and assumptive notion of reasonableness in Western philosophy. I have approached this as a practitioner in the field of international and global social justice education. It is grounded in my life experience as a male, middle class, bilingual Canadian born with Lebanese-Syrian and IrishScottish roots. My intent has been to consider the pedagogical significance of reasonableness, 
since I have come to feel that its broad socio-cultural and legal application lacks an educational perspective. This paper is my small contribution to an age-old dialogue about an age-old concept.

\section{Re-conceiving reasonableness}

Civic education, in its emphasis on the transmission of foundational political principles and practices, has a central place in cultivating reasonableness. However, critically aware citizenship may subordinate procedural and informational civic education approaches (Weber, 2008; Brookfield, 1987). Civic education emphasizes prescription, seeking to inculcate particular concepts of political public reason, deliberation and justice (Parry, 1999).

Reasonableness as critical thinking is not satisfied with this pedagogical objective. Brookfield (1987) argued that we must not become complacent by ceasing to ask "why do we do things this way and not another?" This question differentiates democratic civic from citizenship education. Reflective, critical thinking is central to healthy democratic societies, including how those societies relate across socio-economic, racial and cultural divides, on regional national and global scales (Benhabib, 1989; 1996). We need to learn not only the workings, but the failings and history of our political system. As Stewart-Harawira (2008) explained, we need to understand and integrate alternative concepts of citizenship, especially those of marginalized and colonized peoples. She wrote,

To secure human rights for all requires an urgent re-visioning of the way in which we shape the past, present and future, of the way in which we view relationships and, in particular, of the shape and form of global order. It involves matching the outward exploration of existence with an inward exploration of the meaning of being, the nature of being human and of the purpose of existence. (Stewart-Harawira, 2008, p. 172)

In order to move beyond doctrinal models of reasonableness, we must question our basic assumptions about the conceptual universality of justice, freedom and liberty. In this manner we can come to understand how our notion of rationality arises through our access to certain fundamental capabilities (Sen, 2009). Seen this way, reasonableness is itself a capability, learned through education that enables safe, open-ended, dialogical opportunity where differences can be shared (hooks, 2010; Ghosh \& Abdi, 2004). Following Sen (2009) and Appiah $(2005 ; 2006)$ our capacity for and judgement of one another's reasonableness is based upon what arguments we have learned are possible and the ways in which we have learned they should be given and received. Imagination and creativity are central to shaping and reshaping our national, ethnic and individual identity (Appiah, 2008; Greene, 1995). As Greene (1995) described, nurturing creativity allows us to examine, experientially, the ways in which knowledge and ideas are interpreted and can be re-interpreted. Greene (1995) expounded,

To tap into the imagination is to become able to break with what is supposedly fixed and finished, objectively and independently real. It is to see beyond what the imaginer has called normal or "common-sensible" and to carve out new orders in experience. Doing so, a person may become freed to glimpse what might be, to form notions of what should be and what is not yet. And the same person may, at the same time, remain in touch with what presumably is. (Greene, 1995, p. 19). 
Through creativity and the imagination we can develop new metaphors for our shared fate and develop future-oriented global projects that can ground our moral motivation for global social justice (Care, 2000). The imagination allows us to develop a deeper understanding of the emotional and socio-cultural differences we have as human beings in relation to such lived experience as birth and death (Nussbaum, 2000). "Decolonized" imagination allows us to think deeply and creatively about meanings of a citizenship on global scale and integrate pluralistic perspectives into educational practice (Abdi, 2008). In this way, critical and creative thinking requires us to reframe reasonableness in relation to its qualitative impact.

Culture and politics are influenced by international treaties, comprehensive political doctrines, global deliberative bodies, mass media, global entertainment and fashion industries, and social networking; however, our identity is not so much homogenized by these shifts, as it is hybridized (Appiah, 2005; 2006). According to Nussbaum (2008) and Appiah (2006), it is through contextually-grounded, compassionate interaction with others that we can come to bridge physical and psychological distances that separate us in our ethical choices, including how we give and receive reasons. Creativity, along with critical thinking, enables us to see and listen to each other in our shared humanity, to nurture reasonableness through mutuality. As Mendieta (2009) wrote, "[T]here is no single cosmopolitan vision, but a process at arriving at it through engagement with a dialogical imagination that opens up spaces of mutual transformation" (p. 254). Williams (2009) described such diversity of conceptions of citizenship and cosmopolitanism as "citizenships of globalization" which are bound by "intentional political agency aimed at the common good" (p. 42). Her description of the role of imagination in such a project brings critical thinking into imagination, based upon a central theme - mutuality.

This transformation depends on a dual act of imagination. First, agents must develop a consciousness of the relationships as existing, ongoing structures of social interdependence. Second, they must imagine that the relationship can be made subject to conscious political agency, to regulation aimed at some common good. [...] These two aspects of imagination stand in an iterative and mutually constituting relationship: the possibility of action generates a new understanding of relationship, which generates new possibilities for action. (p. 42).

Creativity and critical thinking can lead to such new understanding; however it is through shared community that we are motivated to "hear and see again". In the words of hooks (2010),

The most exciting aspect of critical thinking in the classroom is that it calls for initiative from everyone, actively inviting all students to thinking passionately and to share ideas in a passionate, open manner. When everyone in the classroom, teacher and students, recognizes that they are responsible for creating a learning community together, learning is at is most meaningful and useful. In such a community of learning there is no failure. Everyone is participating and sharing whatever resource is needed at a given moment in time to ensure that we leave the classroom knowing that critical thinking empowers us. (hooks, 2010, p. 11)

While our moral motivation may be more obligation than will, mutuality is what differentiates compassion from pity, passionate discussions from verbal abuse and inquiry from inquisition. It is through expanding our sense of community, though our understanding, awareness and 
affirmation of our inter-connectedness that we can avert sliding into relativism, for, "if we cannot learn from each other what is right to think and feel and do, then conversation between us will be pointless" (Appiah, p. 31, 2006). Reasonableness, as enacted inter-subjectively and in community, is heightened in importance by global migration, whether through international education, immigration and foreign worker programs, or through forced displacement due to war or natural calamity. As educators in the field of global social justice, we must therefore revisit the characteristics of reasonableness from a frame of their own.

\section{Reasonableness as judgement}

In current discourse, reasonableness is a term that is used widely in relation to global social justice. It is not, however, employed in a uniform manner. Depending on its theoretical perspective, different concepts of reasonableness contrast in significant ways. At one end of the spectrum is a conception of reasonableness that is inflexible and objectivist in its ethical application and universal and ends-oriented in its approach to morality. It is arguable that this closed-ended, hegemonic frame of reasonableness has been omnipresent in the global social justice context (Dryzek, 2006). Comprehensive doctrines of a strict communitarian or realist nature, or in recent times of a "reflexive traditionalization" (Dryzek, 2006, p. 21), fall into this categorization, where a fixed, universal moral system is codified in formalized documentation, insular or aggressive foreign policy, entrenched ethnic or national identities or fundamentalist theology (Dryzek, 2006). Subjective contestation of institutionalized, cultural or religiousembedded dogma is deemed threatening to political, economic, or socio-cultural order and control. Flexibility in ethics is considered a slippery slope, leading to morally-tainted behaviour, diluted doctrine, vulnerability to attack, or deflated global influence, among other perceived dangers and vices. As a source of justification for action, this frame of reasonableness can appear trustworthy and stable, at least amongst those whom the sources of justification are valued and shared (Appiah, 2005). Notions such as "balanced", "modest" and "fair" are firm, yet arguably propagandistic and/or euphemistic. They provide a foundation upon which to judge the reasons of others and, in extreme cases, as a rationale to persecute them. Arguments which acquiesce to, or are at least morally aligned with, the comprehensive doctrine are deemed reasonable. The ends of reasoning supersede a dialogical process, as there is little room for accommodation of particular contexts or subjective interpretation.

As we move from this end of the spectrum, certain brands of political liberalism and cosmopolitanism come into focus. Traditional liberal, contractualist doctrines, not conceived for application in a global context, present a conflicted stasis on the international stage (Fraser, 2009). Individualistic and protective, subjectivity is conflated with constitutional state sovereignty, leading to realist global politics. Flexibility is possible, to a point, so long as fundamental principles of individual liberty are not divested, even at the expense of subverting the practices of divergent, minority cultures (Moore, 1993; Galeotti, 2002). In an imperialist cosmopolitan tradition, individual human rights imbue a masculine, Eurocentric, universal secularity that is deemed "both morally desirable and legally acceptable" and the "absolute and unquestioned standard" (Mendieta, 2009, p. 247). Such an approach requires international governance mechanisms to protect individuals from perceived global social injustice through various means, including legitimating military intervention (Young, 2007). In both contexts, the basic moral principles that underlie proper, ethical behaviour are pre-determined and therefore, 
reasonableness, as judgement, includes a certain degree of objectivity (Rawls, 1971; 1999). This objectivity is codified in some manner; however, it is not inflexible, nor ends-oriented. It would be reasonable to contest a law or ethical norm were it to contradict an enshrined freedom, principle or human right. It would be reasonable to propose new constitutional amendments or human rights if didn't impinge on established, fundamental rights and freedoms (Fives, 2010; Riker, 2008). Process becomes more important and thus, reasonableness begins to take on a deliberative connotation, allowing for more inter-subjective interpretation and exploration.

Frames of process-oriented rationality leads to a more neutral political liberalism such as that proposed by Rawls (1999), where differences in ethical behaviour are tolerated to a much greater degree. Reasonableness comes to have much more competency-based or action-oriented significance (Rasmussen, 2004; Bongiovanni \& Valentini, 2009). Comprehensive doctrines are distanced from public discourse, where overlapping consensus is sought in order to bind 'decent' peoples together in the shared, yet differentiated, enterprise of seeking a fulfilling life (Rawls, 1999). Morality, in relation to reasonableness, is narrower in scope. For example, it may be defined as Rawls' two "moral powers": that of a "capacity for a sense of justice and a capacity for a conception of the good" (Rawls, 1999, p. 92). This frame of reasonableness includes a deeper toleration of difference, attentive to process and dialogue in order to remain adaptable to, and participative in, a changing consensus (Galeotti, 2002; Ferrara, 2004). However, reasonableness is not open-ended. A neutralist liberal conception of reasonableness in pluralist, global context presents an anchored position in its own right.

Reasonable persons are characterized in two ways: First, they stand ready to offer fair terms of social cooperation between equals, and they abide by these terms if others do also, even should it be to their advantage not to; second, reasonable persons recognize and accept the consequences of the burden of judgement, which leads to the idea of the reasonable toleration [in a democratic society]. (Rawls, 1999, p. 177)

Central to this "reasonable toleration" or "reasonable pluralism" that Rawls (1999) encouraged to flourish amongst comprehensive doctrines is the distinction between the public (i.e. political) and non-public (i.e. community, cultural, organizational) spheres of dialogue. However, deliberations on justice and competing conceptions of the good invite dissenting voices and diversity of perspectives. Flexible, inter-subjective, means-oriented particularity is a source of both inspiration and conflict. This creates a tension, tempered through what Habermas (1996) considered to be a thinly constructed, morally-neutral basis of reasonableness. Intersubjectivity is welcomed, yet potentially suppressed if it threatens the neutrality of public deliberation (Young, 2005; Moore, 1993). Reasonableness is subordinated to the social contract in and of itself, glossing over the contract's fundamental moral assumptions (Moore, 1996).

At the other end of this spectrum is a conception of reasonableness which welcomes this perceived threat to neutrality, considering such impartiality either misplaced or impossible to attain (Moore, 1996). Reasonableness, through the discourse ethics proposed by Habermas (1996), comes to denote the proof of normative rightness through dialogue amongst people symmetrically engaged in discourse (Erman, 2006). Reasonableness, in contrast to procedural significance, is the proof of normative rules of discourse ethics, where, through the sharing of different reasons, interlocutors reach an agreed upon "rightness" or "truth", inclusive of both the objective (natural) world and inter-subjective similarities and differences in perspective (Bongiovanni \& Valentini, 2009). With rightfulness constructed through individuals engaged in 
dialogue, the actors are of critical importance. This leads to concepts, such as Fraser's (2009) all-affected principle of just representation, whereby "all those affected by a given social structure or institution have moral standing as subjects of justice in relation to it" (p. 24). Certain peoples are entitled to being involved in a particular dialogue based upon how directly a potential decision or action affects their welfare, wellbeing or way of life. Reasonableness thusly conceived denotes the attainment of shared truth or rightfulness through adherence to basic rules of discourse ethics and through discourse entitlement for all those affected by a perceived incidence of global social injustice.

At this point on the spectrum, impartiality is questioned. Positionality and difference are perceived as entrenched in discourse. Competing comprehensive doctrines are deemed likely to clash, neutrality and impartiality being thin and/or practically unachievable. Where deep conflict and "concrete difference" (Erman, 2006) are likely to exist, reasonableness blurs the distinction between, neutral, public and non-public discourse and the normative hierarchy of discourse ethics (Boswell, 2005; Erman, 2006). Through our individual and group autonomy, reasonableness begins to conflate means and ends, demonstrated in externalized demonstrations of the differences and similarities we share amongst one another (Appiah, 2005). This openmindedness is deemed a positive moral disposition: through interactions with others, we may reach a renewed position, a renewed perception of a situation or a renewed conception of even our most basic moral and ethical bases (Appiah, 2006). This deeply inter-subjective concept of reasonableness intimates how it may be possible for a person or people to be deemed reasonable in their irrationality, where their choices may seem to go against their best interests (Church, 1987; Sen, 2009). It illuminates why we may find that, even though we might disagree entirely with the logic of other people's reasons, we might also still feel they are being reasonable. Reasonableness is thus not adequately defined mono-logically as judgement. It must also be considered in relation to self-respect, identity and community.

\section{Reasonableness as recognition}

To be reflective of the inter-subjective meaning of global social justice, reasonableness must also be defined through recognition, a term in political philosophy that also has varied meanings (Honneth, 1996; Fraser, 2009). Fraser's (2009) frame of "representation" is a requisite constituent for "redistribution" claims in global social justice (p. 21). Her slogan "No redistribution or recognition without representation" (Fraser, 2009, p.21) was based on the premise that without ensuring representation of those people whose livelihoods and wellbeing are affected by certain political, legal and economic decisions, inequality of distribution is inevitable. Such understanding and awareness (perceptual, intuitive and rational) of inequality are only possible when minority, majority, dominant and marginalized voices are included in decision making through deliberative, democratic (i.e. inclusive) processes (Benhabib, 1989; 1996). This form of reasonableness does not presuppose any original positions (i.e. right to individual liberty, property, etc.). Reasonableness is a practical requirement and determinant of inter-subjective global equality in distribution of primary goods and increased global equality in standards of living (Sen, 2009; Nussbaum, 2005a).

In this perspective, reasonableness is learned perceptually, intuitively and rationally through experience. This leads to Nussbaum's (2000; 2008), Sen's (2009) and Appiah's (2008) constructivist perception of ethical identity and of Nussbaum's (2005b) and Sen's (2009) concept of global social justice as being tied to capabilities. Reasonableness, as rationality, perception 
and intuition, would in, Sen's and Appiah's perspective, be differentiated by the lived experience and the attendant social choices that an individual person or a people have had access to in their lifetime. Appiah (2006) wrote,

When we offer judgements, after all, it's rarely because we have applied well-thought-out principles to a set of facts and deduced an answer. Our efforts to justify what we have done - or what we plan to do - are typically made up after the event, rationalizations of what we have decided intuitively. And a good deal of what we intuitively take to be right, we take to be right just because it is what we are used to. (p. 72)

This approach acknowledges that differences in the bases and manners of reasoning are inherent in a pluralistic world and that impartiality falls drastically short of providing answers to complex global issues, such as those associated with refugees and internally displaced peoples (Boswell, 2005). Reasonableness must therefore be asserted in relation to the conditions under which basic human capabilities flourish - such as "being able to have good health, including reproductive health" and "being able to move freely from place to place" (Nussbaum, 2005b, pp. 43-44). Unreasonableness is impervious or indifferent to disparities in human capabilities, explaining why differences in reasoning exist, and why irrationality appears to be omni-present (Sen, 2009). Mutuality is thus a critical aspect of reasonableness, drawing upon the concept of recognition as elucidated by Honneth (1996) and upon Erman's (2007) proposed reframing of reasonableness as reason-giving. Honneth (1996) provided a synthesis of the philosophical and socio-cultural shift towards post-modern conceptions of identity, selfhood and respect, including a threefold concept of "love, rights and solidarity" (Honneth, 1996). Included were: emotional support related to needs and emotions, primary relationships, physical integrity and basic selfconfidence; cognitive respect related to moral responsibility, legal relations (rights), self-respect and social integrity; and social esteem in relation to traits and abilities, community of value (solidarity), self-esteem, honour and dignity (Honneth, 1996, p. 129). In any of these three areas, where recognition is not attained, inter-subjective asymmetrical relations will persist and will threaten the impartial concept of reasonableness inherent in Habermasian discourse ethics (Erman, 2006). Honneth (1996) elaborated,

In modern societies, therefore, social relations of symmetrical esteem between individualized (and autonomous) subjects represent a pre-requisite for solidarity. In this sense, to esteem one another symmetrically means to view one another in the light of values that allow the abilities and traits of the other to appear significant for shared praxis. Relationships of this sort can be said to be cases of 'solidarity', because they inspire not just passive tolerance by felt concern for what is individual and particular about the other person. [...] The fact that 'symmetrical' cannot mean here that we esteem each other to the same degree is already clear from the essential openness to interpretation of every societal value-horizon. (Honneth, 1996, p. 129).

Openness, in Honneth's sense, was that of accepting the fundamental experience of lived difference - that there would rarely be contexts with include symmetrical relations between discourse participants, as idealized in Habermasian discourse ethics (Erman, 2006). Moore (1996) presented this issue succinctly, 
What recent work on the concept of reasonableness needs to do is unpack some of the basic moral premises which make the argument go, and ensure that these are explicitly argued for. There may be no agreement on some issues, but if public justification and reason-giving are important (and who could reasonably reject the practice of reasongiving?), then it must be important to spell out the fundamental assumptions on which one's reason's and arguments are based. (Moore, 1996, p. 177).

It is from this perspective that Erman (2006) proposed a shift from conceiving intersubjective recognition as a search for impartial, transcendent or judgemental frames of reasonableness. She offered "reason-giving" as an alternative focus for practical, intersubjective recognition in relation to deliberative social justice, both locally and globally (Erman, 2007). For Erman (2007), attention to reason-giving rather than reasonableness focused attention on the "Other", highlighting the action-oriented, pluralistic nature of deliberative global politics. Reason-giving cannot be self-centered, rationalized, self-justification; for it to be effective intersubjectively, it must be constitutive of the modes of recognition by Honneth. Erman (2007) explained,

[T]o have agent-relative reasons to accept a moral norm on the basis of a common interest does not mean a strategic compromise on the basis of a plain overlap of interests that is mutually advantageous, which is what compromise means for Habermas. If we reached a compromise solely by pleading to instrumental rationality, we would be motivated to violate the norm as soon as we gained by doing so [...]. The substantive demands of communicative action, taking the form of epistemic and normative attitudes, require that acceptance of a common norm entails a moral commitment, not a strategic move. (p. 618)

As we share our reasons with others, our reason-giving must demonstrate recognition of the plurality of lived experience, interpretation, perceived and real inequality, and the misrepresentation and misdistribution that permeate our global context. In this sense, reasonableness demands self-reflection and potential changes in behaviours, attitudes, and legal, political and/or social systems in relation to both public and non-public reasoning. Such a shift is not analytical, but relational, inclusive not only of the act of reason-giving, but of reasonreceiving as well.

\section{Reasonableness as reason-giving and receiving}

As has been shown through this discussion, reasonableness as judgement and as recognition, spans many different meanings, both complementary and contrastive. To consider the full meaning of reasonableness, I have developed an analytical-relational model, with reasongiving and reason-receiving as its practical force (see Figure 1). This is influenced by Erman's $(2006$; 2007) alignment of communicative action with recognition, where reasonableness is differentiated from reason-giving in its dialogical, inter-subjective significance. Erman wrote,

Through the processes of individualization and socialization we learn not only how to argue for or against a moral principle by anticipating others' responses and objections but 
also how to give and take in social interaction. Since relations between respondents from this perspective are viewed as integrated in the speaker, communicative action is more than following linguistic rules by raising validity claims. (Erman, 2006, p. 388).

Erman differentiated the moral agency of reason-giving and reason-receiving from pure reason-receiving, in the case of asymmetrical, vulnerable relationships between the giver (agent) and receiver (agent-addressee). Her focus remained upon the moral agent, who by virtue of engaging in dialogue with others incorporated both reason-giving and reason-receiving. If one was to engage in dialogue with someone and not consider them capable of receiving reasons, or if one was to speak "at" rather than "with" an interlocutor, then moral agency, seen as "interaction and mutuality, as well as between subject, person, similarity and difference" ceases to have relevance (Erman, 2006, p. 389). For pedagogical purposes, while this concept of communicative moral agency is adhered to, both modes of reason-giving and reason-receiving are noted in the model presented. This is because reason-giving may be approached and experienced differently than reason-receiving, and because power relations can be explored in their complexity.

\section{Analytic and relational modes of reason-giving and receiving}

In order to conceptualize the practical, lived meaning and associated pedagogical implications of reasonableness, new terms need to be introduced. These are analytical reasongiving and receiving and relational reason-giving and receiving. Within each of these modes is a continuum of analysis and lived relations with others, including variations in individual cognitive and affective abilities.

Analytical reason-giving and receiving. This mode refers to the weighing or evaluating of facts, opinions, beliefs as well as the frames of analyses that are employed. Emphasis is on emotion and rationality, including feelings and emotional reactions as elements of evaluation and analysis. Analytical reason-giving and receiving move from being unreflective to prescriptive to exploratory.

Unreflective analysis. At one end is an unpredictable, non-reflective disposition. Reactions to discourse contexts and external stimuli are impulsive. This may be learned, may be due to cognitive limitations or may be related to distress and/or extenuating circumstances, among other factors.

Prescriptive analysis. In the middle of this continuum is a mode based upon strict concepts and parameters. This includes basing one's reason-giving and receiving upon preconceived perceptions about how one should/ought to feel/think/judge in a particular situation drawing from religion, political-ethical norms, and other comprehensive or highly individuated, or collectivist doctrines.

Exploratory analysis. At the other end of this continuum is a mode that is open to new conceptual frameworks and sceptical of absolutisms and comprehensive doctrines. Analytic reflection includes understanding of positionality and is constructivist and empirical in nature, valuing experiencing and testing new ideas and hypotheses. 
Figure 1: Integrated Model of Analytical and Relational Reason-Giving and Receiving

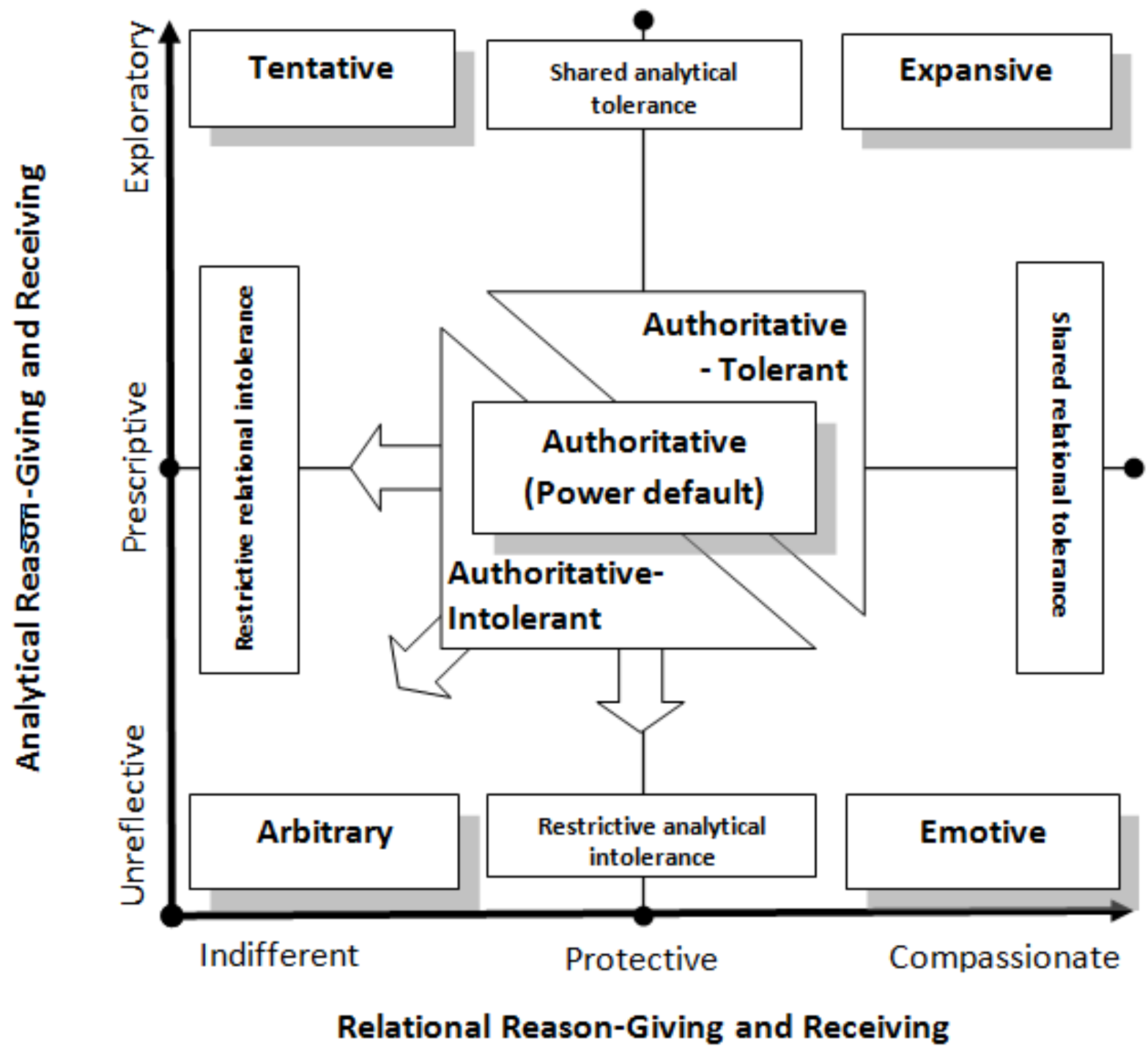

Relational reason-giving and receiving. This second mode focuses upon recognition, moving along a continuum from indifferent to protective to compassionate relations.

Indifferent relations. At one end of the spectrum, is indifference to recognition, and even threatening to others' physical and/or social integrity and dignity. It can be both intentional and unintentional in nature, due to circumstance and/or psychological wellbeing.

Protective relations. In the middle of this continuum is a mode that is loving, legalistic and/or solidaristic, but is also ethnocentric, prejudicial or exclusive.

Compassionate relations. At the other end of this continuum are compassionate relations beyond socio-economic, cultural, national and other boundaries, whether explicitly or implicitly. 


\section{Reason-giving and receiving typology}

These modes lead to intersections of analysis and lived relation, culminating in seven types of reason-giving and receiving, and two emphases: tolerant and intolerant.

Relational intolerance. This emphasis of intolerance is unreflective and protective. Relational intolerance is based on such things as rigid group solidarity. It is experienced as exclusion from group membership or deliberation with limited rationalization or as prejudice.

Analytical intolerance. This emphasis of intolerance is prescriptive and indifferent. It is legalistic or integrated into institutional norms and experienced through pre-determined, prejudicial outcomes from hearings.

Relational tolerance. This emphasis of tolerance is prescriptive and compassionate. Relational tolerance is experienced as inter-subjective recognition associated with self-esteem, mutual appreciation of traits and abilities and dignified treatment of cultural diversity.

Analytical tolerance. This emphasis of tolerance is exploratory and protective. Analytical tolerance is also legalistic in nature but is open to rethinking ways of accommodating differences. It is tolerant of different comprehensive doctrines; however would not necessarily show concern related to poverty or inequality.

Arbitrary reason-giving and receiving. This type is an unreflective-indifferent mode. It can be both unpredictable and threatening to others' self-confidence, self-respect and selfesteem. The bases for evaluative judgements are unclear and inconsistent, leading to possible uncertainty, insecurity and confusion.

Tentative reason-giving and receiving. This type is an exploratory-indifferent mode. Tentative reason-giving and receiving can seem rigidly intellectual, asserting highly objectivist or ambivalent positions and, while actively listening, not resulting in action. Indifference and its effects can be clearly articulated, but of little to no concern.

Emotive reason-giving and receiving. This type is an unreflective-compassionate mode. Emotive reason-giving and receiving is driven by compassion and intuition. Dialogue may be emotionally charged and subjectively emphatic without an apparent analytic basis.

Authoritative reason-giving and receiving. This type is a prescriptive-protective mode. It is realist in nature, grounded in bounded solidarities and fixed conceptions of justice based on nationality, political system, theology and philosophy. It is usually aligned with tolerant/intolerant emphases, and may be seen as a power default. Where there is an imbalance of power relations between interlocutors, its intolerant emphasis may be enacted.

Authoritative-intolerant reason-giving and receiving. Intolerant, authoritative reasongiving and receiving shifts the prescriptive-protective mode toward either a prescriptiveindifferent or unreflective-protective emphasis. In the first case, rigid rules, traditions and practices may result in forms of communicative disrespect, such as imposition, exclusion, denigration or insult. In the second case, solidarity and communitarian bonds take precedence over anachronistic or potentially disabling practices, such that reason-giving and receiving may be solidaristic and self-propagating even when a position may be self-defeating or inattentive to potentially valuable viewpoints.

Authoritative-tolerant reason-giving and receiving. Tolerant, authoritative reasongiving and receiving shifts the prescriptive-protective mode toward either a prescriptivecompassionate or exploratory-protective emphasis. Differences in opinion, belief, moral/cultural/political practices and values are either sought to be understood through mutuality, or are integrated into a formalized model for "neutral" inter-subjective dialogue in 
public forums. In either case, the integrity of particular position is sought to be maintained while simultaneously being open to discussing potentially antithetical propositions and behaviours.

Expansive reason-giving and receiving. This type is an exploratory-compassionate mode. Expansive reason-giving and receiving is tolerant both analytically and relationally. It is open to learning, adapting to or creating new concepts, practices and social and cultural norms. Difference, asymmetry and change are welcomed, even anticipated.

\section{Conclusion: \\ Reasonableness as reflective practice}

Reframing reasonableness in the manner I have undertaken draws attention to the contrast between mono-logical and dialogical approaches to global social justice and to the inevitability of unreasonableness. In the mono-logical view, reasonableness is pre-defined through different comprehensive doctrines or political theories. Consequently, there will always be those who do not adhere to what is deemed reasonable, and are thus judged as unreasonable. Miller's (1953/1979) characters in The Crucible faced such a dualism, to the point where it no longer mattered what they said or did to exonerate themselves. As a lived relation with others, such inter-subjective unreasonableness will persist, whether viewed as a conflict between monological comprehensive doctrines or perceived as a contrast between modes of reason-giving and receiving. However, the inevitability of unreasonableness does not detract from the project of elucidating the characteristics that, through their learning, could lead to increased reasonableness in relation to deliberative global social justice. It is to this matter which I now turn in this concluding section of the paper, with attention to three different levels of reflective practice: selfawareness; inter-subjective awareness; and intercultural awareness.

The first aspect of reflective practice in reason-giving and receiving is that of one's selfawareness of one's own reason-giving and receiving tendencies. Does one reason more analytically or relationally? Is one protective or tentative? Does one espouse tolerance? In The Crucible, one of the main characters, John Proctor, wrestles with conflicting modes of reasongiving and receiving. This is indicated in the descriptions of Proctor's emotions, moving from thoughtfulness to anger, as he deals with multiple issues at once: his adulterous affair with Abigail; Abigail's accusation of his wife as engaging in witchcraft; and his relationships with his neighbours, who are either charged by or acting as agents of the court. In this excerpt, Proctor struggles with how to approach the court with the knowledge that Abigail is inventing the charges being laid against innocent people, and inadvertently reveals a falsehood he had kept from his wife.

ELIZABETH: I would go to Salem now, John - let you go tonight.

PROCTOR: I'll think on it.

ELIZABETH, with her courage now: You cannot keep it, John.

PROCTOR, angering: I know I cannot keep it. I say I will think on it!

ELIZABETH, hurt, and very coldly: Good, then let you think on it. She stands and starts to walk out of the room.

PROCTOR: I am only wondering how I may prove what she told me, Elizabeth. If the girl's a saint now, I think it is not easy to prove she's fraud, and the town gone so silly. She told me it in a room alone - I have no proof for it. 
ELIZABETH: You were alone with her?

PROCTOR, stubbornly: For a moment, alone, aye.

ELIZABETH: Why, then, it is not as you told me.

PROCTOR, his anger rising: For a moment, I say. The others came in soon after.

(Miller, 1953/1979, p. 53)

Throughout the play, Miller (1953/1979) underscores this internal struggle that Proctor faces, culminating in his final decision to act upon his conviction, sentencing himself to death by not condemning others through associating them with witchcraft.

Self-awareness of one's approach to reason-giving and receiving is, I believe, a critical element of global social justice education, increasing one's ability to handle ethical dilemmas and complex relationships. A practical exercise, drawn from this model, would be to have students think about their ideal mode of reason-giving and receiving, and to consider questions such as: When I am acting reasonably, this looks like/means/feels like [blank]?; When I am acting unreasonably, this looks like/means/feels like [blank]? This can be further explored by asking questions such as: Are there times when you might not keep to your ideal mode of reasongiving and reason-receiving?; What might these moments be? This leads to the inter-subjective nature of reasonableness, where one's reason-giving and reason-receiving is inherently experienced in specific contexts and with specific individuals.

In the excerpt from The Crucible, the inter-subjective relationship between Elizabeth and Proctor is prescient. The way in which they give and receive reasons for their respective positions are both analytical and relational, moving from emotiveness to tentativeness, as they attempt to retain an authoritative hold on a situation that is increasingly out of their control. Reflecting on their interaction deepens our awareness of the lived meaning of reasonableness, as we must ask questions such as: How would I act in such a situation?; Why are Elizabeth and John acting in this way?; or Would I act any differently? Returning to self-awareness, we can reframe questions of lived reasonableness, as: When someone acts unreasonably with you, what does this look like/feel like? Exploring past experiences can also open to the inter-subjective, or cross-cultural, lived meaning of reasonableness. Reflecting on past experiences and considering how reasons were verbally and non-verbally expressed could provide a means to consider the variability of reasonableness in lived experience. It also can be expanded to include discussion on the intercultural dimensions of reasonableness, in terms of how it is defined and enacted in different cultural contexts.

Developing this capacity for self- and inter-subjective awareness can be applied to current events. Interactions between individuals can be reflected upon, including dialogue between international leaders, local activists with lobby groups, or in comment/discussion boards on particular news items, among other possibilities. Developing a reflective capacity to deconstruct how reasons are given and received can, I believe, increase a person's ability to consider the variability in how dialogue and discussion take place on the global stage or in relation to global issues. This can lead to reflecting upon the intersection between the intersubjective, or cross-cultural, and our collective general values or dispositions, or the intercultural (Hofstede, 2001). This intersection is evident in the excerpt from The Crucible, where Proctor contemplates the challenge he will face in trying to discredit Abigail, who had achieved a form of saintliness in the eyes of certain people and the court. The meta-cultural constraints of his accusation of fraud were self-evident, as he ultimately disagreed with the underlying logic and 
authority of the court itself, including its brand of religious supernaturalism. The court, through Judge Danforth, had become relationally restrictive and analytically intolerant.

Considering reason-giving and receiving from an intercultural perspective can include looking more critically at such international bodies as the UN and considering how they approach decision-making on complex international issues. It can also include discussions and in-depth study on famous figures, such as Mahatma Ghandi, Mother Theresa, or Martin Luther King Jr., to reflect upon who judged them as being reasonable or unreasonable in their actions and deeds and why this was so. Consideration of what reasonableness looks like, from a behavioural perspective, feels like, from an inter-subjective experience, and is perceived as from an intercultural perspective can help broaden our understanding of the lived meaning of reasonableness. I believe our capacity for global social justice can be strengthened if we develop a sensitivity to, or understanding of, the preferred reason-giving and receiving mode(s) of different peoples. Intercultural differences in how reasons are given and received can be explored through research and dialogue with those who may have a closer understanding of those affected by the situation. A good example of this within the Canadian context is how we address Aboriginal issues in our educational system. An intercultural reason-giving and receiving approach would be grounded in inter-subjective experiential learning and sharing, where selfreflection upon one's analytical and relational reasoning on matters of shared concern, such as Treaty rights, would seek a deepening of knowledge and sensitivity to both similarities and differences in personal knowledge, history, culture and life experience.

The position taken in this paper is that of moral agency and thus the subject of interest is the learner. Through cultivating relational compassion and analytical exploration, I believe that a person's thinking and knowing can be expanded to comprehend the plurality of (un)reasonableness and its multiplicity in origins, from (mis)recognition to (mal)distribution, to (mis)representation. Storytelling, drama, critical analysis, journals, self-assessment, role-plays and community service learning are all pedagogical approaches where different modes of reasongiving and receiving can be reflected upon, experienced and challenged. In this way, reasonableness as judgement and recognition may be comprehended in their relevance to intellectual analysis, inter-subjective relations and intercultural contexts. Through selfawareness, critical thinking and mutuality, such an approach to global social justice education may enable us, as learners and teachers, to revive the notion of reasonableness as a dynamic, complex lived relation with others.

\section{References}

Abdi, A. (2008). De-subjecting subject populations: Historico-actual problems and educational possibilities. In Abdi, A. \& Schultz, L. (Eds.), Educating for human rights and global citizenship, (pp. 65-80). Albany, NY: State University of New York Press.

Appiah, K. (2005). The ethics of identity. Princeton, NJ: Princeton University Press.

Appiah, K.. (2006). Cosmopolitanism: Ethics in a world of strangers. New York, NY: W.W. Norton.

Appiah, K. (2008). Experiments in ethics. Cambridge, MA: Harvard University Press. 
Benhabib, S. (1989). Liberal dialogue versus a critical theory of discursive legitimation. Liberalism and the moral life, N. Rosenblum (Ed.), 143-156. Cambridge, MA: Harvard University Press.

Benhabib, S. (1996). Toward a deliberative model of democratic legitimacy. In S. Benhabib, Democracy and difference: Contesting the boundaries of the political, 67-93. Princeton, NJ: Princeton University Press.

Beitz, C. (2008). A state of nature. In T. Brooks (Ed.), The global justice reader (pp. 18-50). Malden, MA: Blackwell Publishing. (Reprinted from Political theory and international relations, pp. 13-63, Princeton, NJ: Princeton University Press).

Bongiovanni, G. \& Valentini, C. (2009). Reciprocity, balancing and proportionality: Rawls and Habermas on moral and political reasonableness. In Reasonableness and Law, Law and Philosophy Library (86). G. Bongiovanni, et al. (Eds.), 81-107.

Boswell, C. (2005). The ethics of refugee policy. Burlington, VT: Ashagate Publishing Company.

Brookfield, S. (1987). Developing critical thinkers: Challenging adults to explore alternative ways of thinking and acting. San Francisco: Jossey-Bass.

Care, N. (2000). Decent People. New York, NY: Rowman \& Littlefield Publishers, Inc.

Church, J. (1987). Reasonable irrationality. Mind, 96 (383), 354-366.

Dryzek, J. (2006). Deliberative global politics. Maiden, MA: Polity Press.

Erman, E. (2006). Reconciling communicative action with recognition: Thickening the "inter of intersubjectivity. Philosophy and social criticism, 32 (377), 377-400.

Erman, E. (2007). Conflict and universal moral theory: From reasonableness to reason-giving. Political Theory, 35 (5), 598-623.

Ferrara, A. (2004). Public reason and the normativity of the reasonable. Philosophy \& Social Criticism, 30 (5-6), 579-596.

Fives, A. (2010). Reasonableness, pluralism, and liberal moral doctrines. Journal of Value Inquiry, 44, 321-339.

Fraser, N. (2009). Scales of justice: Reimagining political space in a globalizing world. New York, NY: Columbia University Press.

Galeotti, A. (2002). Toleration as recognition. New York, NY: Cambridge University Press.

Ghosh, R. \& Abdi A. (2004). Education and the politics of difference: Canadian perspectives. Toronto, ON: Canadian Scholars' Press.

Greene, M. (1995). Releasing the imagination: Essays on education, the arts and social change. San Francisco, CA: Jossey-Bass Publishers.

Habermas, J. (1996). The inclusion of the other: Studies in political theory. Cambridge, MA: The MIT Press.

Hofstede, G. (2001). Culture's consequences: Comparing values, behaviors, institutions and organizations across nations ( $2^{\text {nd }}$ ed.). Thousand Oaks CA: Sage Publications.

Honneth, A. (1996). The struggle for recognition: The moral grammar of social conflicts. Cambridge, MA: The MIT Press.

hooks, bell. (2010). Teaching critical thinking: Practical wisdom. New York, NY: Routledge.

Martine, J. (1993). The Crucible: Politics, property, pretence. Twayne Publishers: New York, NY.

Mendieta, E. (2009). From imperial to dialogical cosmopolitanism. Ethics and Global Politics, 2(3), pp. 241-258. 
Miller, A. (1979). The Crucible. Penguin Books: New York, NY. (Original, 1953, Viking Press; New York, NY).

Moore, M. (1993). Foundations of liberalism. Oxford, UK: Clarendon Press.

Moore, M. (1996). On reasonableness. Journal of Applied Philosophy, 13 (2), 167-178.

Nussbaum, M. (2000). Emotions and social norms. Culture, thought and development. L. Nucci, G. Saxe \& E. Turiel (Eds.), pp.41-63. Mahwah, NJ: Lawrence Erlbaum Associates, Publishers.

Nussbaum, M. (2005). Beyond the social contract: Capabilities and global justice. In The political philosophy of cosmopolitanism, G. Brock \& H. Brighouse (Eds.), pp. 196218.

Nussbaum, M. (2005). Capabilities as fundamental entitlements: Sen and social justice. In Amartya Sen's work and ideas; A gender perspective, B. Agarwal, J. Humphries \& I. Robeyns, (Eds.), 34-61. New York, NY: Routledge.

Nussbaum, M. (2008). Upheavals of thought: The intelligence of emotion ( $8^{\text {th }}$ ed.). New York, NY: Cambridge University Press.

Parry, G. (1999). Constructive and reconstructive political education. Oxford Review of Education, 25 (1/2), 23-38.

Rasmussen, D. (2004). Defending reasonability: The centrality of reasonability in the later Rawls. Philosophy \& Social Criticism, 30 (5-6), 525-540.

Rawls, J. (1971). A theory of justice. Cambridge, MA: Belknap Press.

Rawls, J. (1999). The law of peoples. Cambridge, MA: Harvard University Press.

Riker, W. (2008). Democratic legitimacy and the reasoned will of the people. In D.A. Reidy and W.J. Riker (Eds.), Coercion and the state (pp. 77-94). Springer Science + Business Media.

Sen, A. (2009). The idea of justice. Cambridge, MA: Belknap Press.

Stewart-Harawira, M. (2008). Traditional peoples and citizenship in the new imperial order. In A. Abdi \& L. Shultz (Eds.), Educating for human rights and global citizenship, (pp. 159-175). Albany, NY: SUNY Press.

Weber, E. (2008). Dewey and Rawls on education. Human Studies, 31, 361-382.

Williams, M. (2009). Citizenship as agency within communities of shared fate. In Unsettled legitimacy: Political community, power and authority in a global era. S. Berstein and W. Coleman (Eds.), pp.33-52. Vancouver, BC: UBCPress.

Young, S. (2005). The (un)reasonableness of Rawlsian rationality. South African Journal of Philosophy, 24(4), 308-320.

Young. M. (2007). Global challenges: War, self-determination and responsibility for justice. Maiden, MA: Polity Press. 